\title{
PEMBELAJARAN FISIKA MENGGUNAKAN PEMODELAN UNTUK MENINGKATKAN PEMAHAMAN KONSEP PADA MATERI HUKUM NEWTON GRAVITASI DAN HUKUM KEPLER
}

\author{
Mimi Rohazal Yaumi, Sutopo, Parno \\ e-mail:mimiryaumi@gmail.com \\ Universitas Negeri Malang \\ e-mail: mimiryaumi@gmail.com
}

\begin{abstract}
Abstrak
Penelitian ini bertujuan untuk mengetahui peningkatan pemahaman konsep peserta didik melalui pembelajaran dengan pemodelan. Pembelajaran dengan pemodelan menitikberatkan pada model untuk menjelaskan fenomena gaya gravitasi, medan gravitasi, hukum Kepler, dan aplikasinya pada gerak satelit. Metode Penelitian yang digunakan adalah mixed method dengan jenis embedded experimental design. Penelitian dilakukan di kelas X MIPA di salah satu sekolah Kabupaten Pasuruan dengan subyek penelitian 131 peserta didik. Analisis dilakukan secara deskriptip kualitatif untuk mengetahui peningkatan pemahaman konsep peserta didik, kesulitan peserta didik selama pembelajaran, dan kebermanfaatan pembelajaran dengan pemodelan. Hasil penelitian menunjukkan terjadi peningkatan pemahaman konsep peserta didik setelah mengikuti pembelajaran dengan pemodelan pada materi hukum Newton gravitasi dan hukum Kepler. Peningkatan pemahaman konsep peserta didik dapat dilihat dari nilai $d$-effect size sebesar 2,12 yang termasuk lebih besar dari rata-rata dan nilai $\mathrm{N}$-gain sebesar 0,49 yang tergolong medium atas. Pembelajaran ini dapat memudahkan peserta didik dalam memahami (1) konsep medan gravitasi, (2) konsep gaya gravitasi, (3) hukum I, II, III Kepler, (4) aplikasi hukum III Kepler untuk menentukan kecepatan satelit. Penelitian lebih lanjut dapat dilakukan dengan menganalisis miskonsepsi pada Hukum Newton Gravitasi dan Hukum Kepler.
\end{abstract}

Kata Kunci: Pemodelan, Hukum Newton Gravitasi, Hukum Kepler, Pemahaman Konsep

\section{Abstract}

This study aims to determine the increase in students' conceptual understanding through learning by modeling. Learning by modeling focuses on the model to explain the phenomenon of gravitational force, gravitational field, Kepler's law, and its application to satellite motion. The research method used is a mixed method with the type of embedded experimental design. The study was conducted in one of Pasuruan Regency schools with research subjects consist of 131 students of X MIPA. The analysis was carried out with qualitative descriptive to determine the increase of the students' conceptual understanding, students' difficulties during learning, and the advantages of learning by modeling. The results of the study showed an increase in students' conceptual understanding through learning by modeling on Newton's law of gravity and Kepler's law. Improved conceptual understanding of students can be seen from the value of the d-effect size of 2.12 which includes greater than average and $\mathrm{N}$-gain value of 0.49 which is classified as an upper medium. This way of learning facilitated students in understanding (1) the concept of gravitational fields, (2) the concept of gravitational force, (3) Kepler's law I, II, and III, (4) Kepler III legal application to determine satellite speed. Further research can be done by analyzing misconceptions in Newton's Law of Gravity and Kepler's Law.

Keywords: Modeling, Newton's Law of Gravity, Kepler's Law, Conceptual Understanding 


\section{PENDAHULUAN}

Praktik dalam pembelajaran fisika memiliki peranan yang penting untuk mengaitkan pada peristiwa sehari-hari. Praktik dalam pembelajaran fisika memberikan pengalaman langsung kepada peserta didik dalam menghadapi suatu permasalahan. Praktik juga dapat membantu peserta didik dalam mengaitkan fenomena di alam dengan fenomena lainnya. Pembelajaran fisika di sekolah diharapkan dapat memberikan bekal bagi peserta didik dalam menguasai konsep dan cakap dalam menyelesaikan permasalahan di kehidupan nyata melalui teknologi (Kemendikbud, 2015). Hal ini pun sesuai dengan salah satu tujuan penting dari pembelajaran fisika yang yaitu untuk mengantarkan peserta didik memahami secara mendalam konsep-konsep dasar dalam fisika sehingga mampu menerapkannya untuk memecahkan masalah (Docktor \& Mestre, 2014)

Salah satu konsep materi yang diajarkan di kelas X MIPA SMA adalah hukum Newton gravitasi. Materi hukum Newton gravitasi erat kaitannya dengan interaksi antar benda di kehidupan sehari-hari. Interaksi tersebut dinamakan gaya gravitasi. Gaya gravitasi merupakan interaksi dua benda, namun dua benda tidak saling bersentuhan (Serway, 2010). Hal ini menjadi masalah bagi guru dalam menjelaskannya kepada peserta didik. Hal tersebut juga menjadi permasalahan dalam memahaminya mengingat interaksinya berupa gaya tarik-menarik pada jarak tertentu. Selain itu, gaya gravitasi merupakan interaksi antar benda yang tidak dapat dilihat secara kasat mata langsung (Serway, 2010).

Pemahaman peserta didik tentang gaya masih menjadi kesulitan panjang dalam sejarah penelitian fisika (Brookes dan Etkina, 2009). Dalam pembelajaran hukum Newton gravitasi di SMP, peserta didik hanya mengonstruksi pengetahuan tentang gaya gravitasi secara kualitatif. Namun, dalam materi hukum Newton gravitasi di SMA, peserta didik tidak hanya diajarkan menghapal tentang hukum tersebut. Peserta didik juga menganalisis konsep gaya dan merepresentasikan secara matematis (NGSS, 2013). Oleh karena itu, strategi khusus diperlukan untuk menjelaskan konsep gaya gravitasi melalui konsep medan dan mencegah adanya miskonsepsi pada peserta didik.

Selain gaya gravitasi, materi hukum Newton gravitasi juga membahas tentang medan gravitasi dan hukum Kepler. Medan gravitasi merupakan alasan adanya gaya gravitasi yang merupakan gaya tak sentuh. Interaksi gaya antar benda djelaskan melalui medan. Peserta didik mengetahui medan sebagai suatu daerah. Padahal medan dalam materi hukum Newton gravitasi merupakan besaran yang penting untuk menjelaskan gaya (Haliday dan Resnick, 2010). Sedangkan hukum Kepler menjelaskan tentang gerak planet. Gerak planet terhadap matahari tidak dapat dilihat secara kasat mata. Kepler 
menggunakan data astronomis untuk menjelaskan model gerak planet (Haliday dan Resnick, 2010). Data astronomi tersebut dijelaskan melalui penggambaran khusus.

Pembelajaran yang berbasis inkuiri (praktik) dan sesuai dengan materi hukum Newton gravitasi dibutuhkan untuk membimbing peserta didik agar aktif dalam mengkonstruksi konsep selama pembelajaran. Pembelajaran konstruktivisme berbasis penyelidikan (inkuiri). Salah satu pembelajaran yang konstruktivisme adalah modeling instruction (pembelajaran dengan pemodelan). Pembelajaran pemodelan menekankan pada penggunaan model untuk menjelaskan suatu fenomena. Pembelajaran dengan pemodelan ini dapat membantu peserta didik dalam memahami konsep. Pengetahuan peserta didik akan berkembang jika disertai model bergambar (Oliviera, 2012). Model merupakan cara ilmuwan dalam membangun pengetahuan. IImuwan juga menggunakan model untuk menggambarkan pemahamannya terhadap sistem (atau sebagian dari sistem) dalam penyelidikan, untuk membantu mengembangkan pertanyaan dan penjelasan serta mengkomunikasikan ide ke orang lain (NRC, 2012). Model juga membantu peserta didik berpikir logis, fleksibel, dan sistematis dalam memahami fisika (Wells et al, 1995). Pembelajaran dengan pemodelan ini tidak hanya membantu peserta didik dalam memahami suatu fenomena, namun juga membantu peserta didik dalam berargumen tentang fenomena tersebut. Pembelajaran dengan pemodelan juga diharapkan dapat memberikan manfaat untuk mempermudah memahami konsep bagi semua kelompok peserta didik.

\section{METODE}

Metode penelitian yang digunakan adalah mixed methods jenis embedded experimental design (Creswell, 2012). Desain eksperimen yang digunakan adalah one group pretest-posttest.Penelitian dilaksanakan di kelas X MIPA di salah satu SMA Negeri Kabupaten Pasuruan. Penelitian dilaksanakan pada semester genap tahun pelajaran 2016-2017. Penelitian dilakukan tanggal 30 Januari 2017 hingga 28 Februari 2017. Jumlah subjek dalam penelitian ini adalah 131 peserta didik. Penelitian dilaksanakan dalam empat tahap. Penelitian diawali dengan pretest dengan menggunakan 11 soal pilihan ganda. Penelitian dilanjutkan dengan pembelajaran dengan pemodelan. Selanjutnya dilakukan posttest dengan soal yang sama. Namun, dalam posttest peserta didik menjawab disertai alasan. Tahap terakhir adalah analisis dari hasil data yang diperoleh.

Instrumen yang digunakan dalam penelitian ini adalah tes, lembar pengamatan, dan foto dan video. Instrumen lembar pengamatan merupakan instrumen yang berisi checklist keterlaksanaan pembelajaran dan catatan lapangan pengamat. Foto dan video 
merupakan instrumen penunjang dalam mendeskripsikan pembelajaran. Foto dan video juga merupakan bukti fisik keterlaksanaan pembelajaran.

Analisis dilakukan secara kualitatif dan kuantitatif. Kekuatan peningkatan dari skor pretest ke posttest dapat diukur dengan menggunakan d-effect size (Morgan, et al, 2004) dan rata-rata gain ternormalisasi (Hake, 1998). Nilai d-effect size dapat dihitung menggunakan persamaan $d=\frac{\text { Mean }_{\text {past }}-\text { Mean }_{\text {pre }}}{\left(S D_{\text {pre }}+S D_{\text {post }}\right) / 2}$ (Morgan, et al, 2004). Rata-rata gain ternormalisasi juga mendeskripsikan seberapa kuat peningkatan skor pretest ke posttest. Nilai gain score dapat dihitung dengan persamaan $\langle g\rangle=\frac{\text { (posttest)-(pretest) }}{\text { skormaksimum-(pretest) }}$ (Hake, 1999). Pemahaman konsep peserta didik juga dideskripsikan dari respon jawaban peserta didik pada masing-masing soal.

\section{HASIL DAN PEMBAHASAN}

Deskripsi statistik skor dan nilai $N$-gain peserta didik dapat dilihat dalam Tabel 1. Dari hasil perhitungan, nilai rata-rata posttest lebih tinggi dari pada pretest sehingga terjadi peningkatan pemahaman konsep pada pembelajaran dengan pemodelan ini.

\begin{tabular}{llll}
\multicolumn{4}{l}{ Tabel 1. Deskripsi Statistik Skor Pretest dan Posttest } \\
\hline Statistik & Pretest & Posttest & N-gain \\
\hline Mean & 4,29 & 7,56 & 0,45 \\
Nilai Minimum & 1 & 3 & $-0,6$ \\
Nilai Maksimum & 8 & 11 & 1,00 \\
Standar Deviasi & 1,47 & 1,6 & 0,31 \\
Skewness & $-0,13$ & $-0,21$ & $-0,71$ \\
Std. Error of Skewness & 0,21 & 0,21 & 0,21 \\
\hline
\end{tabular}

Catatan : Skor tes dalam skala 1 hingga 11

Hasil dari perhitungan $d$-effect size menunjukkan nilai 2,12 yang termasuk dalam kategori " jauh lebih besar dari rata-rata” (Morgan et al, 2004). Hasil ini menunjukkan bahwa pembelajaran pemodelan efektif dalam meningkatakan pemahaman konsep peserta didik pada materi hukum Newton gravitasi dan hukum Kepler. Besar peningkatan nilai pretest dan posttest juga dapat dinyatakan dalam nilai gain rata-rata ternormalisasi ( $N$-gain). Besar perhitungan $N$-gain dari rata-rata kelas sebesar 0,49 yang tergolong "medium atas" (Sutopo dan Waldrip, 2014).

Pemahaman konsep peserta didik juga dapat diketahui dari respon jawaban peserta didik. Frekuensi jawaban benar peserta didik dapat dilihat pada Gambar 1. Gambar tersebut juga menunjukkan gambaran peningkatan jawaban benar peserta didik. 


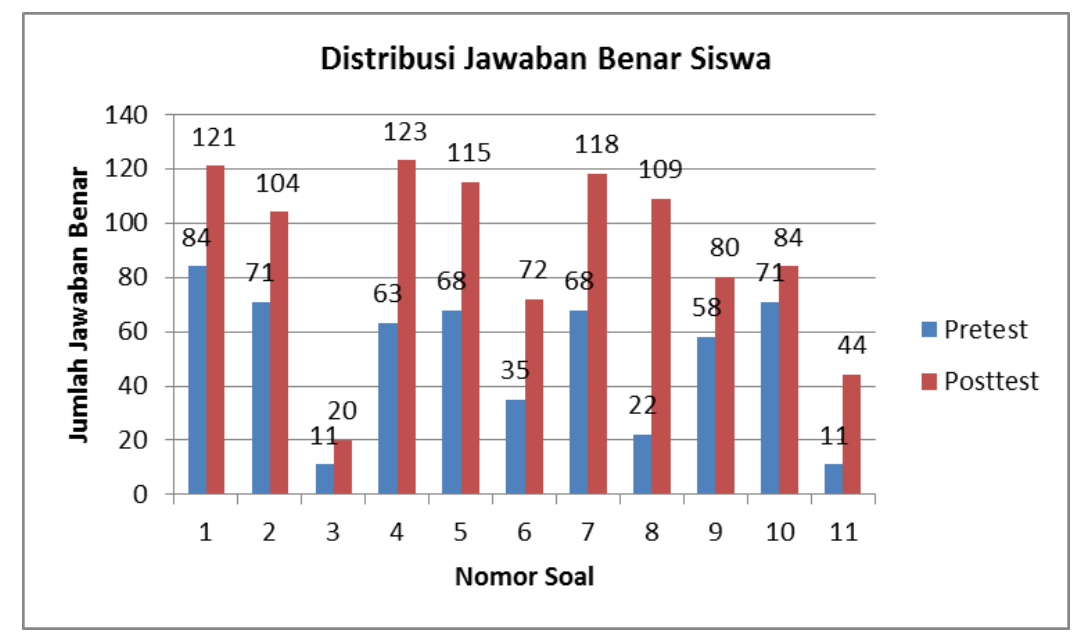

Gambar 1. Frekuensi jawaban benar peserta didik

Gambar 1 menunjukkan skor yang tinggi pada soal nomor 9. Soal nomor 3 memiliki peningkatan yang rendah. Untuk mengetahui respon peserta didik pada soal-soal tersebut, maka dilakukan analisis kualitatif. Soal nomor 9 dimaksudkan untuk mengetahui pemahaman peserta didik dalam hukum I dan II Kepler. Peningkatan terjadi karena peserta didik telah mengetahui pernyataan secara mendetail pada masing-masing hukum. Pergeseran jawaban peserta didik dapat dilihat pada crosstabulation Tabel 2 berikut.

Tabel 2. Crosstabulation Jawaban Peserta didik pada Soal No. 9

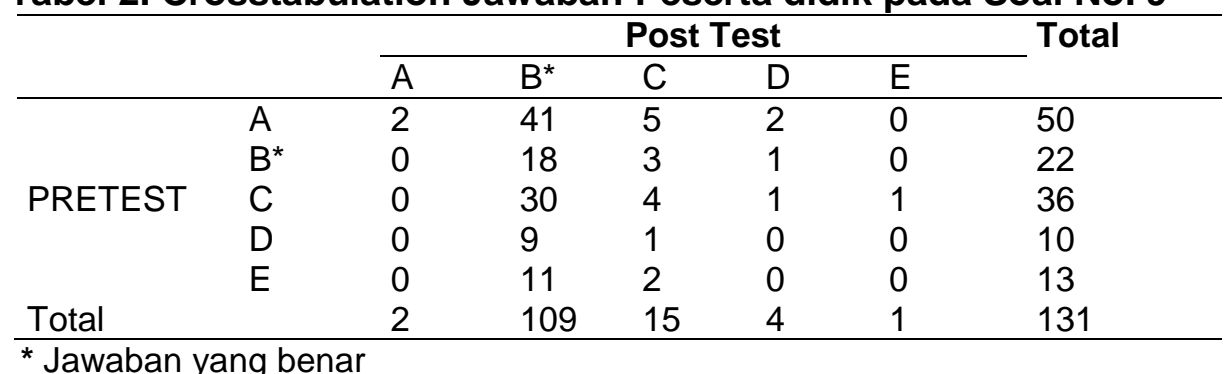

Tabel 2 menunjukkan terdapat 22 peserta didik yang menjawab benar pada pretest. Jumlah tersebut meningkat pada posttest menjadi 109 peserta didik. Selain itu, terdapat 18 peserta didik yang konsisten menjawab benar pada pretest dan posttest. Pemahaman peserta didik dipertegas pada alasan jawaban yang dituliskan peserta didik. Pada alasan jawaban peserta didik, sebagian besar peserta didik memberikan alasan dengan menuliskan pernyataan hukum I, II, dan III Kepler. Sebagian peserta didik lainnya menuliskan kesesuaian hukum I, II, dan III pada maisng-masing pernyataan. Sebagai contoh pada pernyataan 5 , peserta didik menuliskan bahwa pernyataan tersebut sesuai dengan hukum I Kepler yang menyatakan bahwa planet mengelilingi Matahari dengan lintasan elips dengan Matahari pada salah satu fokus elips.

Soal nomor 3 bertujuan untuk mengetahui pemahaman peserta didik terhadap konsep gaya gravitasi. Soal ini mengukur pemahaman konsep peserta didik tentang 
rumusan gaya gravitasi dan gaya gravitasi pada masing-masing benda. Rumusan gaya gravitasi $F=\frac{G m_{1} m_{\underline{z}}}{r^{2}}$ menunjukkan bahwa nilai gaya antara kedua benda adalah sama. Dan dari gambar telah diketahui bahwa gaya antara dua benda tersebut saling berlawanan arah $\left(\vec{F}_{12}=-\vec{F}_{21}\right)$. Pergeseran jawaban peserta didik dapat dilihat dari crosstabulation pada Tabel 3.

Tabel 3. Crosstabulation Jawaban Peserta didik pada Soal No. 3

\begin{tabular}{|c|c|c|c|c|c|c|}
\hline & & \multicolumn{4}{|c|}{ Post Test } & \multirow{2}{*}{ Total } \\
\hline & & $A^{*}$ & $B$ & $\mathrm{C}$ & $\mathrm{D}$ & \\
\hline \multirow{5}{*}{ PRETEST } & $A^{*}$ & 0 & 6 & 4 & 1 & 11 \\
\hline & B & 7 & 11 & 11 & 1 & 30 \\
\hline & C & 8 & 20 & 34 & 2 & 64 \\
\hline & $D$ & 5 & 6 & 6 & 4 & 21 \\
\hline & $E$ & 0 & 2 & 1 & 2 & 5 \\
\hline Total & & 20 & 45 & 56 & 10 & 131 \\
\hline
\end{tabular}

\section{* Jawaban yang benar}

Peserta didik menjawab benar pada pretest sebanyak 11 peserta didik, sedangkan saat posttest terdapat 20 peserta didik yang menjawab benar. Peserta didik yang menjawab benar telah memahami aksi-reaksi pada gaya gravitasi antar dua benda. Namun, sebagian benar peserta didik terkecoh pada perbedaan massa pada kedua benda. Sebagain besar peserta didik menjawab bahwa benda 2 yang mempunyai massa yang lebih besar akan menghasilkan gaya gravitasi yang lebih besar pula. Namun, jawaban tersebut adalah salah jika berhubungan dengan gaya interaksi antar dua benda. Dalam hal ini peserta didik mengalami naïve conceptions. Pada awal pembelajaran, peserta didik menganalisis besaran yang mempengaruhi gaya gravitasi. Dari pembelajaran awal tersebut, peserta didik mengetahui bahwa gaya dan massa sebanding sehingga pemikiran tersebut juga digunakan pada gaya gravitasi pada dua benda. Naïve conceptions terjadi karena peserta didik berpatokan pada pengetahuan awal tanpa memikirkan konten yang dibahas (Reiner, 2000). Hal ini pun memunculkan miskonsepsi pada gaya gravitasi dua benda.

\section{SIMPULAN}

Kesimpulan dari penelitian ini adalah peningkatan pemahaman konsep tergolong rendah ( $d$-effect size sebesar 2.12) dan tergolong medium ( $N$-gain sebesar 0.49). Pembelajaran pemodelan memerlukan waktu untuk mebantu peserta didik dalam memahami konsep. Guru sebaiknya lebih sering dalam berkomunikasi secara tanya jawab maupun diskusi kecil. Guru lebih menambah pertanyaan konsep untuk menguatkan peserta didik dalam membangun konsep melalui pemodelan. Penelitian selanjutnya dapat dilkukan dengan menganalisis lebih mendalam pada miskonsepsi hukum Newton gravitasi dan hukum Kepler. 


\section{DAFTAR PUSTAKA}

Brookes, D. T., \& Etkina, E. 2009. "Force," Ontology, and Language. Physical Review Special Topics-Physics Education Research, 5(1), 010110.

Docktor, J.L. \& Mestre, J.P. 2014. Synthesis Of Discipline-Based Education Research in Physics. Physical Review Special Topics - Physics Education Research, 10 (2): 020119.

Halliday, D., Walker, J., \& Resnick, R. (2013). Fundamentals of physics. John Wiley \& Sons.

Hake, R. R. 1998. Interactive-engagement versus traditional methods: A sixthousandstudent survey of mechanics test data for introductory physics courses. American journal of Physics, 66(1), 64-74.

Hestenes, D. 1987. Toward a Modeling Theory of Physics Instruction. American Journal of Physics. 5 (5), 440-454.

Hestenes, D. 1997. Modeling methodology for physics teachers. In AIP Conference Proceedings (pp. 935-958). IOP Instiutute of Physics Publishing LTD.

Kemendikbud. 2014. Peraturan menteri pendidikan dan kebudayaan republik indonesia nomor 59 tahun 2014 tentang kurikulum 2013 sekolah menengah atas/madrasah aliyah. Jakarta.

Morgan, A. G., Leech, L. N., Gloeckner, W. G. \& Barret, C. K. 2004. SPSS for Introductory Statistic Use and Interpretation (Second edition). London: Lawrence Erlbaum Associates Inc.

NGSS Lead States. 2013. Next generation science standards: For states, by states. National Academies Press.

NRC. 2012. A Framework for K-12 Science Education. United States of America: National Academy Press.

Reiner, M., Slotta, J. D., Chi, M. T., \& Resnick, L. B. 2000. Naive physics reasoning: A commitment to substance-based conceptions. Cognition and instruction, 18(1), 134.

Serway, R. A., \& Jewett, J. W. (2018). Physics for scientists and engineers with modern physics. Cengage learning.

Sutopo \& Waldrip, B. 2014. Impact of A Representational Approach on Students' Reasoning and Conceptual Understanding in Learning Mechanics. International Journal of Science and Mathematic Education, 12: 741-765, (Online), diakses pada 25 November 2016.

Wells, M., Hestenes, D. \& Swackhamer, G. 1995. A Modeling Method For High School Physics Instruction. American Journal of Physics. 606-619. 